\title{
Biomarcadores da fisiologia reprodutiva em equinos
}

Biomarkers of reproductive physiology in equine

\author{
Verônica La Cruz Bueno ${ }^{1,2^{*}}$, Henrique Boll de Araujo Bastos ${ }^{1}$, Sandra Fiala Rechsteiner ${ }^{1,2}$ \\ ${ }^{1}$ REPROLAB - Faculdade de Veterinária, UFRGS, Porto Alegre-RS, Brasil; \\ ${ }^{2}$ HISTOREP - Instituto de Biologia, Universidade Federal de Pelotas, UFPEL, Pelotas-RS, Brasil
}

\begin{abstract}
Resumo
Vários estudos encontraram biomarcadores gênicos associados à fertilidade tanto na fêmea como no macho. Este trabalho tem o objetivo de revisar os marcadores gênicos que estão envolvidos na fisiologia da reprodução equina. Diferentes genes foram associados na égua com a fisiologia ovariana e uterina, já no garanhão a presença de genes silenciados na especializada célula espermática vem sendo tema de pesquisas, demonstrando a importância desses genes após a fecundação. Diferente de outras espécies domésticas de interesse zootécnico, os equinos são valorizados como indivíduo, animais de alto padrão genético atingem valores elevados de comércio e reprodução. Os reprodutores equinos, como os homens, recebem tratamento médico para a infertilidade. Assim a identificação de marcadores positivos e negativos referentes à fertilidade, pode ser uma ferramenta para auxiliar a detecção de alterações que comprometam a vida reprodutiva da fêmea e do macho equino.
\end{abstract}

Palavras-chave: Fertilidade, expressão gênica, reprodução equina.

\section{Abstract}

Several studies demonstrated genetic biomarkers associated with fertility in both the female and the male. The current study aims to review the genetic markers that are involved in the physiology of equine reproduction. In the mare, different genes have been associated to ovarian and uterine physiology, whereas in the stallion the presence of silenced genes in the specialized sperm cell has been the subject of research, demonstrating the importance of these genes after fertilization. Unlike other domestic species of zootechnical interest, horses are valued as individuals and animals of superior genetic standard reach high values of trade and reproduction. Equine, like men, receive medical treatment for infertility. Thus, the identification of positive and negative markers referring to fertility, can be a tool to assist in the detection of changes that compromise the reproductive life of the female and the male horse.

Keywords: Fertility, gene expression, equine reproduction.

\section{Introdução}

Modernas técnicas de biologia molecular vêm sendo utilizadas em estudos envolvendo a determinação da relação entre a ocorrência de variações no DNA com características fenotípicas, contribuindo para abordagens preventivas na medicina humana e animal (Leon et al., 2011). O interesse no estudo da reprodução equina é fomentado cada vez mais como ferramenta para acelerar o ganho genético e competitividade na indústria equestre (Hinrichs, 2013). Diferente de outras espécies domésticas de interesse zootécnico, os equinos são valorizados como indivíduo e animais de alto padrão genético atingem valores elevados de comércio e reprodução (Chowdhary et al., 2008; Varner et al., 2008). Os reprodutores equinos, assim como os homens, geralmente recebem tratamento médico para a infertilidade (Ing et al., 2014). A extração de ácidos nucleicos (DNA e RNA) é o primeiro passo para a realização da maioria das metodologias de Biologia Molecular. É possível se obter DNA e RNA a partir de inúmeros tipos de tecidos e células (Barttlet et al., 2003). Marcadores biológicos ou biomarcadores são entidades que podem ser medidas experimentalmente e indicam a ocorrência de uma determinada função normal ou patológica de um organismo (Garban et al., 2006). A identificação de genes e marcadores associados com características economicamente importantes, como a reprodução, permite que os pesquisadores desenvolvam testes específicos de diagnóstico e elaborem medidas preventivas de manejo

Correspondência: veronicalacruzbueno@hotmail.com Recebido: 29 de julho de 2020

Aceito: 27 de maiode 2021 
e tratamento (Brosnahan et al., 2010). Este trabalho tem o objetivo de revisar os biomarcadores gênicos que estão envolvidos na fisiologia da reprodução equina.

\section{Reconhecimento Materno da Prenhez}

O estabelecimento e manutenção da prenhez dependem da comunicação entre o embrião e a mãe durante o período de pré-implantação. $\mathrm{O}$ equino é uma das poucas espécies domésticas em que o sinal derivado do embrião para o reconhecimento da prenhez não foi desvendado até o momento. Para manter a gestação, um concepto móvel deve ser reconhecido pelo útero antes de 14 dias pós-ovulação (Klohonatz et al., 2015). O endométrio e o embrião expressam uma ampla gama de Transportadores de Soluto (SLC) (Klein e Troedsson, 2011).

A cápsula embrionária é formada por glicoproteínas similares à mucina, secretada, pelo menos em parte, pelo trofoblasto. As mucinas são uma família de glicoproteínas de alto peso molecular que se encontram geralmente cobrindo as superfícies luminais dos órgãos epiteliais, incluindo o útero na maioria das espécies. A expressão de mucina 1 (MUC1) parece ser regulada pela progesterona e o estradiol e está relacionada com os efeitos antiadesivos do útero na prevenção da implantação prematura. Na espécie equina, foi demonstrado que o RNAm da $M U C 1$ se expressa no endométrio tanto de éguas prenhes como das não prenhes entre os dias 11 e 18 da prenhez/ciclo estral respectivamente, assim como no trofoblasto da maioria dos embriões obtidos nesse período (Gillies et al., 1999). Através de imunofluorescência se determinou que a proteína de $M U C 1$ foi expressa uniformemente nas superfícies apicais do epitélio luminal e glandular. Entretanto, a intensidade de coloração de MUC1 foi superior no corno gravídico que no não gravídico nos dias de obtenção das amostras (dias 14, 17, 21, 27 da prenhez/ciclo estral) (AlRamadan et al., 2002).

Klein e Troedsson (2011) demonstraram que em embriões do dia 14 (em comparação aos do dia 8) a expressão genica da osteopontina (SPP1) foi reduzida. A SPP1 é uma proteína de origem extracelular que se une às 25 integrinas para promover a união e a comunicação célula-célula, o que contribui à prolongada pré-implantação nesta espécie. Foi detectado pela técnica de imunofluorescência que a intensidade de coloração da SPP1 no endométrio equino é superior nas amostras obtidas nos dias 21 e 27 quando comparadas com as dos dias 14 e 17 de prenhez (Al-ramadan et al., 2002).

Fatores de crescimento e citocinas derivadas do útero desempenham papéis essenciais na regulação do pré-implante e desenvolvimento do concepto. Em várias espécies, o Fator de Crescimento de Fibroblastos-2 (FGF2) promove embriogênese, migração de células trofoblásticas e adesão. A expressão do gene $F G F 2$ foi investigada no endométrio e trofectoderma equino durante o ciclo estral e início da gestação. Este estudo concluiu que durante a terceira e quarta semana de gestação o epitélio luminal do endométrio equino produz $F G F 2$, que pode desempenhar um papel no desenvolvimento e adesão de trofoblastos (Ruijter-Villani et al., 2013).

Foram verificadas alterações na expressão gênica do endométrio de éguas prenhes, éguas vazias e após o reconhecimento materno da prenhez (MRP) com o objetivo de identificar possíveis genes envolvidos, através da técnica PCR em tempo real (RT-PCR). Dez genes foram identificados como tendo maiores ou menores níveis de expressão no endométrio de éguas prenhes versus éguas vazias nos dias 14, 16 e 18 pós-ovulação $(\mathrm{P}<0,001)$. Cada um desses genes pode ter um papel fundamental na modificação do útero para que haja o reconhecimento da gestação. Os genes que apresentaram maior expressão no endométrio de éguas prenhes foram: Juxtaposed with another zinc finger 1-like (JAZF10), S100 calcium binding protein $G(S 100 G)$, Solute Carrier Family 36 Member 2 (SLC36A2), Methyltransferase-like protein 7A-like (METTL7A), Eukaryotic translation initiation factor 2-alpha kinase 3 (EIF2AK3), Dickkopf 1 homolog (DKK1) and Adrenomedullin (ADM). Já os genes com menor expressão no endométrio de éguas prenhes foram: Retinaldehyde dehydrogenase 1-like (RALDH1), Estrogen receptor 1 (ESR1) and phospholipase A2 (SPLA2) (Klohonatz at al., 2015).

A RT-PCR revelou uma maior abundância de mRNA de Vascular endothelial growth factor $(V E G F)$ durante a gestação em éguas, apoiando o conceito de que o concepto desempenha um papel ativo na direção da vasculogênese no útero e, assim, estabelecendo nutrição hemotrófica que dá suporte à gestação após o implante (Silva et al., 2011). Outro gene de interesse o Solute Carrier Family 39 Member 2 (SLC39A2), que é regulado positivamente na presença de embriões equinos, desempenha um papel importante na homeostase do zinco durante a prenhez, também afeta o ferro e a homeostase do cálcio. Quando os níveis de zinco são baixos, SLC39A2 é crucial para o desenvolvimento normal do embrião. O SLC39A2 foi altamente regulado positivamente no endométrio de equídeos durante a gestação e auxilia na regulação do transporte de aminoácidos e ácidos graxos durante o desenvolvimento inicial do embrião 
(Smits et al., 2016).

$\mathrm{O}$ efeito do lado do corpo lúteo na expressão gênica uterina e na localização da proteína do Receptor de estrogênio $\alpha(E R \alpha)$ e Receptor de progesterona $(P R)$ em éguas cíclicas e éguas prenhes 13 dias após a ovulação (dia 0) foram investigadas. Biópsias transcervicais foram realizadas para coletar endométrio ipsilateral e contralateral em relação ao lado do corpo lúteo no dia 13 pós-ovulação em éguas cíclicas $(n=6)$ e prenhes $(n=6)$. A expressão do receptor foi determinada por imunohistoquímica e a expressão do transcrito por RT-PCR. O corno contralateral apresentou maior porcentagem de células positivas para $E R \alpha$ do que o corno ipsilateral, mas o lado não afetou a $P R$. $E R \alpha$ mostrou baixa coloração e nenhum efeito principal de prenhez foi encontrada, mas éguas prenhes tiveram menor expressão de proteína de $P R$. O corno contralateral tendeu a apresentar maior expressão do gene $E R \alpha$ e $P R$. A expressão relativa do mRNA $E R \alpha$ foi menor no grupo prenhe. A interação do estado reprodutivo e lado do corpo lúteo tendeu para afetar a expressão de mRNA de $P R$, pois éguas prenhes tinham um conteúdo de mRNA de $P R$ mais baixo no corno ipsilateral do que éguas cíclicas. Até onde sabemos, este é o primeiro estudo que descreve o comportamento dos receptores de esteroides no endométrio de éguas em relação ao lado do corpo lúteo (Kalpokas et al., 2018).

Ciclos alúteos (AL) foram induzidos em éguas para avaliar os efeitos da privação de progesterona na expressão gênica de embriões e endométrio coletados 8 dias após a ovulação. Sete éguas cíclicas foram inseminadas artificialmente. As éguas controle receberam solução salina, já as éguas do grupo AL receberam Prostaglandina F2 alfa (PGF2 $\alpha$ ), duas vezes ao dia, nos dias 0,1 e 2 e uma vez ao dia nos dias 3 e 4, sendo o zero o dia da ovulação. As éguas foram monitoradas até retornarem ao estro e foram artificialmente inseminadas. Quatro transcritos mostraram aumento da expressão em embriões desenvolvidos durante os ciclos AL: estrogen receptor (ESR1), P19 lipocalin (P19), apolipoprotein B $(A P O B)$ e progesterone receptor $(P G R)$. Quatro transcritos mostraram aumento no endométrio desenvolvido durante os ciclos AL: SPLA2, PGR, ESR1, fibroblast growth factor 9 (FGF9) e quatro transcritos apresentaram diminuição na sua expressão: P19, connective tissue growth fator (CTGF), interferon épsilon (IFNE), hexokinase 2 (HK2). Embriões e endométrio em um ambiente privado de progesterona durante AL induzidos demonstraram expressão transcrita alterada. Esses resultados indicam que níveis adequados de progesterona podem ser um mediador chave do ambiente embrião-materno apropriado durante o período de pré-implantação (Leisinger et al., 2019).

\section{Biomarcadores em Éguas}

$\mathrm{Na}$ égua, diferentes genes foram associados à fisiologia ovariana (Bastos et al., 2014), oocitária (Leon et al., 2011), embrionária (Mortensen et al., 2010) e uterina (Centeno et al., 2018). Os genes Metaloproteinases 1 (MMP-1) e Metaloproteinases 2 (MMP-2) foram apontados como genes importantes em todo o processo de remodelamento tecidual, o qual ocorre durante o desenvolvimento folicular em éguas. O receptor de hormônio luteinizante, presente no ovário e no epitélio superficial ovariano, pode ter um papel fundamental para o mecanismo de sinalização para a produção das metaloproteinases, visto que os ovários que apresentaram maiores concentrações de receptor de hormônio luteinizante tiveram maior expressão gênica de $M M P s$ (Bastos et al., 2014). A expressão de $M M P 2$ também já foi verificada nas células da granulosa em éguas, sugerindo seu envolvimento no processo de desenvolvimento folicular (Sessions et al., 2009).

Estudos realizados em humanos também servem como base para estudos em animais, baseado no conhecimento e resultados obtidos no âmbito genômico sobre a influência do polimorfismo em problemas reprodutivos de mulheres, o gene da Protein 53 (P53) torna-se um importante alvo de pesquisa na reprodução equina. Um estudo foi realizado avaliando a expressão de genes envolvidos no processo de apoptose no complexo cumulus-oócito equino, onde foi observado que os genes SURVIVIN e P53 são marcadores de viabilidade em potencial. Oócitos equinos morfologicamente saudáveis apresentam maior expressão de SURVIVIN e menor expressão de P53, comparados a células do cumulus (Leon et. al., 2011).

O complexo cumulus-oócito foi objeto de estudo para determinar a expressão de genes ligados à viabilidade celular e apoptose antes e após vitrificação. Os resultados observados na expressão do gene Bone Morphogenetic Protein 15 (BMP15) sugerem a permanência da viabilidade celular em complexos cumulus-oócito equinos, porém, os resultados observados na expressão do gene BCL2Associated X Protein (BAX) sugerem a ativação do processo de apoptose nas células expostas ao processo de vitrificação (Polenz et al., 2016). Embriões produzidos in vitro, assim como embriões de baixa qualidade produzidos in vivo, apresentaram altas concentrações relativas de Heat Shock Protein 70 
(HSP70) e baixo mRNA 18S, quando comparados a embriões produzidos in vivo classificados de alta qualidade. Os pesquisadores concluíram que oócitos equinos foram sensíveis ao calor durante o período final de maturação in vitro, e responderam ao estresse térmico com aumento na taxa de expressão gênica de HSPA1A:18S, a qual foi medida nos blastocistos resultantes. Os embriões produzidos in vitro (incluindo os controles) apresentaram altos níveis de expressão de HSPA1A mRNA relativos ao $18 \mathrm{~S}$ rRNA, quando comparados aos embriões produzidos in vivo, sugerindo resposta aos insultos ambientais (Mortensen et al., 2010).

Outro estudo examinou as diferenças quantitativas e temporais no mRNA para o receptor hormônio luteinizante (LHR), amphiregulin (AREG) e epiregulin (EREG) em células da granulosa, fosfodiesterase phosphodiesterase (PDE) $4 D$ em células do cumulus e PDE3A acoplada à G-proteincoupled receptor 3 (GPR3), growth differentiation factor 9 (GDF9) e BMP15 em oócitos. As amostras foram coletadas de folículos dominantes de éguas jovens (3-12 anos) e velhas (>20 anos) em 0, 6, 9 e 12 $\mathrm{h}$ após a administração de hormônio luteinizante recombinante equino. O mRNA do LHR diminuiu após $0 \mathrm{~h}$ em éguas jovens, sem efeito do tempo em éguas velhas. Para ambas as idades, a expressão gênica de $A R E G$ foi elevada às $6 \mathrm{e} 9 \mathrm{~h}$ e a expressão de $E R E G$ foi elevada às $9 \mathrm{~h}$, com maior expressão nas éguas velhas do que nas jovens. Expressão de $P D E 4 D$ foi aumentada em $6 \mathrm{~h}$ nas velhas e $12 \mathrm{~h}$ nas jovens. A expressão de GPR3 atingiu o pico às 9 e $12 \mathrm{~h}$ em ambas as idades. Expressão de $P D E 3 A$ aumentou às $6 \mathrm{~h}$, com o aumento maior em éguas jovens e velhas às 6 e $9 \mathrm{~h}, G D F 9$ e $B M P 15$ foram maiores em jovens que idosos, com pico às $6 \mathrm{~h}$. Os resultados apoiam uma associação na expressão de genes essenciais para a maturação folicular e oocitária antes da ovulação (Campos-Chillon et al., 2015).

A expressão gênica das $M M P-1, M M P-2$ e $T N F-\alpha$ no endométrio de éguas com diferentes graus de fibrose foi quantificada. Ambas as $M M P s$ apresentaram valores de expressão inversa, sugerindo ações opostas na cascata de formação de fibrose endometrial. A expressão de $T N F-\alpha$ foi semelhante entre as categorias estudadas, sugerindo uma ação importante na sinalização da fisiologia endometrial das éguas (Centeno et al., 2018).

A infertilidade por causas infecciosas na égua é clinicamente bem descrita, porém pouco se sabe sobre reação de fase aguda sistêmica e respostas imunológicas locais que acompanham a endometrite equina. Um estudo monitorou marcadores selecionados da reação de fase aguda na circulação sistêmica e correlacionou com a resposta imune local inata no útero durante endometrite infecciosa. Seis éguas adultas receberam uma dose intrauterina de infusão de $10^{9}$ UFC de Escherichia coli. Biópsias endometriais foram obtidas $3,12,24,48$ e 72 h após a inoculação. A endometrite infecciosa resultou em reação sistêmica de fase aguda, com concentrações significativamente aumentadas de proteínas séricas de fase aguda, como a amilóide A e fibrinogênio. Uma maior expressão de Interleucina 1 (IL-1), TNF- $\alpha$, Interleucina 8 (IL-8) e Interleucina 10 (IL-10) foi observada às $3 \mathrm{~h}$ (Christoffersen et al., 2010).

Posteriormente, Christoffersen et al., (2012) verificaram a expressão gênica de interleucinas (IL), TNF- $\alpha$, antagonista do receptor de IL-1 ( ra) e amilóide sérico A (SAA) em tecido endometrial e leucócitos circulantes em resposta à inoculação uterina de Escherichia coli em éguas. Antes da inoculação, as éguas foram classificadas como resistentes ou susceptíveis à endometrite persistente com base na resposta inflamatória uterina. As biópsias endometriais foram obtidas 3,12, 24 e $72 \mathrm{~h}$ após inoculação. Comparadas aos níveis de uma biópsia controle (obtida no estro subsequente), éguas resistentes mostraram uma regulação positiva $I L-1 b, I L-6, I L-8$ e $T N F-\alpha 3 \mathrm{~h}$ após a inoculação de Escherichia coli, enquanto éguas susceptíveis apresentaram aumento do gene expressão de $I L-6$ e $I L-1 \mathrm{ra}$. Éguas susceptíveis tiveram uma expressão gênica significativamente menor de $T N F-\alpha, I L-6$ e aumentaram expressão de $I L-1 r a 3 \mathrm{~h}$ após inoculação de Escherichia coli em comparação com éguas resistentes. Éguas susceptíveis mostraram uma resposta inflamatória prolongada com níveis aumentados de expressão gênica da razão $I L-1 b, I L-8, I L-1 r a$ e $I L-1 b$ durante todo o período do estudo $(72 \mathrm{~h}$ ), enquanto os níveis em éguas resistentes retornaram aos níveis de controle do estro em $12 \mathrm{~h}$ (Christoffersen at al., 2012).

Durante o estro a expressão de mRNA para Interleucina-1-beta $(I L-1 \beta), T N F-\alpha, I L-6$ foi maior em éguas susceptíveis do que em éguas resistentes a endometrite antes de um estímulo antigênico (Fumoso et al., 2003). Um quadro semelhante foi observado para a $I L-8$ (Fumoso et al., 2006). Os resultados obtidos sugerem que o estímulo deveria ultrapassar certo limiar para induzir uma transcrição coordenada de citocinas e que este limiar seria menor nas éguas susceptíveis do que nas resistentes (Fumoso et al., 2003). As proteínas expressas estariam relacionadas tanto à contratilidade uterina, quanto ao processo inflamatório, concordando com achados anteriores de que éguas susceptíveis apresentariam um nível exacerbado de resposta inflamatória (Fumoso et al., 2003).

As b-defensinas são pequenas proteínas catiônicas com potente atividade imunorregulatória e 
antimicrobiana. Uma pesquisa sistemática do genoma de Equus caballus que identificou um cluster de novos genes $b$-defensina no cromossomo 22, que é homólogo a um aglomerado no cromossomo 13 de bovino foi realizada. Foram encontradas correspondências para ortólogos de 13 dos genes bovinos, denominados b-defensinas eqUinas (eBD) 115, eBD116, eBD117, eBD119, eBD120, eBD122a, eBD123, $e B D 124, e B D 125, e B D 126, e B D 127, e B D 129$ e eBD132. Fragmentos de tecido foram obtidos do testículo, epidídimo e ducto deferente de três garanhões e do ovário, oviduto, corno uterino, útero, colo do útero e vagina de três éguas. Os genes b-defensina mostraram padrões distintos de expressão específicos da região. A expressão preferencial no epidídimo e no oviduto sugerem um possível papel na imunoproteção do aparelho reprodutor equino ou na fertilidade (Johnson et al., 2016).

A retenção das membranas fetais (RFM) é uma enfermidade pós-parto prevalente em éguas, pode ser definida como a falha parcial ou liberação incompleta do alantocório $3 \mathrm{~h}$ após o parto. A incidência varia de $2 \%$ a $10 \%$ dos partos em éguas de raça leve, mas pode chegar a 30\% - 54\% nas raças pesadas (Canisso et al., 2013). Durante o parto, várias citocinas pró-inflamatórias são liberadas na placenta, o que facilita ainda mais as contrações uterinas, expulsão do feto e membranas fetais. Uma resposta inflamatória alterada nas éguas pode resultar em RFM. Amostras do endométrio e do alantocórion foram coletadas de 15 éguas com RFM e de 29 éguas de controle dentro de $2 \mathrm{~h}$ após o parto. A expressão do mRNA das proteínas $I L-1 b, I L-6$ e $T N F-\alpha$ foi analisada por RT-PCR e Western blot. Em éguas com RFM, a expressão de mRNA da $I L-1 b$ no endométrio $(\mathrm{p}<0,05)$ e $I L-6$ na alantocórion (p $<0,0001)$ foi maior do que nas éguas que expulsaram fisiologicamente as membranas fetais. A maior expressão de $I L-6$ no alantocórion foi confirmada por Western blot. O aumento da expressão de $I L-6$ no alantocórion e $I L-1 b$ no endométrio pode refletir uma resposta imune local que leva ao descolamento das membranas fetais. A baixa expressão de $T N F-\alpha$ pode sugerir que essa citocina não está envolvida na expulsão das membranas fetais (Jaworska e Janowski, 2019).

Endometrite persistente induzida por cobertura é uma das principais causas de infertilidade em éguas. Um estudo foi desenvolvido com o objetivo de avaliar a perfusão genital e a expressão de citocinas inflamatórias em éguas classificadas como suscetíveis ou resistentes. Dez éguas foram examinadas diariamente durante o estro até seis dias após a ovulação induzida por hCG por dois ciclos estrais, sendo inseminadas 24 horas após a indução da ovulação em um ciclo com sêmen morto congelado e no outro ciclo com solução salina estéril. Biópsias endometriais foram obtidas $24 \mathrm{~h}$ antes, 2 e 7 dias após a infusão, e expressões de mRNA de IL1B (Interleukin 1b), IL6 (Interleukin 6), IL8 (Interleukin 8), IL10 (Interleukin 10), TNF (Tumor necrosis factor a), CASP3 (Caspase 3) e COX2 (Cyclooxygenase 2) foram determinados por RT-PCR. A expressão de mRNA endometrial de $I L 1 B$ aumentou em 2 dias após a infusão de sêmen morto em éguas suscetíveis, e a expressão de $I L 10$ aumentou em 7 dias após a infusão dentro do éguas resistentes. O mRNA da IL6 foi aumentado em éguas suscetíveis em comparação com éguas resistentes aos 2 dias após a infusão. Em resumo, uma infusão intrauterina de sêmen morto aumenta o fluxo sanguíneo uterino resistência e altera a expressão do gene endometrial de citocinas inflamatórias por pelo menos sete dias, mas não altera afetam o suprimento sanguíneo ovariano e a função lútea em éguas suscetíveis Endometrite persistente induzida por cobertura (Lüttgenau et al., 2021).

\section{Biomarcadores no Garanhão}

Os marcadores genéticos podem ser úteis na seleção de garanhões. Como são conhecidos muitos genes que influenciam a fertilidade em outras espécies, especialmente em humanos e em camundongos, é provável que mais genes em garanhões se tornem conhecidos (Sieme e Distl, 2012).

Klonisch et al. (2003) estudaram a diferença da expressão e mutação gênica em garanhões criptorquidas. Nenhuma mutação no Insulin Like Factor 3 (INSL3) ou Leucine-rich Repeat-Containing G Protein-coupled receptor 8 (LGR8) foi identificada em garanhões criptorquidas. Curiosamente, foi observado que em garanhões criptorquidas unilaterais, a expressão do INSL3 é aumentada e a expressão do $L G R 8$ desregulado na criptorquidia versus no testículo descendente.

Em garanhões Hannoverianos, a associação do genoma, para estimar os valores reprodutivos do componente paterno, no índice de prenhez por ciclo estral foi estudada. Um total de 228 garanhões Hannoverianos foram genotipados usando o Equine SNP50 Beadchip. Os polimorfismos não codificantes

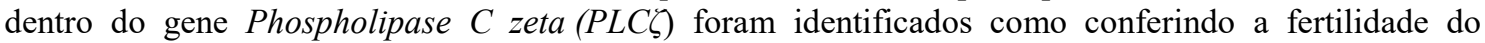
garanhão (Schrimpf et al., 2014). Outro estudo utilizando seis garanhões subférteis com taxa de prenhez inferiores a $30 \%$ demonstrou quantidades inferiores de $P L C \zeta$ em cinco garanhões quando comparada com garanhões controle (Zambrano et al., 2016). Foram realizadas clonagens para a caracterização da $P L C \zeta$ em espermatozoides de equinos com o objetivo de caracterizar a atividade extracelular e intracelular de 
$\mathrm{Ca}^{+2}$ e a expressão da $P L C \zeta$ no espermatozoide equino. Microinjeções do gene foram realizadas em oócitos equinos, onde foram observadas aumento das ondas de $\mathrm{Ca}^{+2}$ (Sylvia et al., 2012).

No momento, pouco se sabe sobre a potencial ligação entre a deficiência de $P L C \zeta$ e subfertilidade ou infertilidade no garanhão, embora a diminuição dos níveis de expressão de $P L C \zeta$ tenha sido previamente relatada em sêmen de garanhões inférteis (Gradil et al., 2006). No equino o gene é expresso sob a cabeça do espermatozoide e na região da cauda (Sylvia et al., 2012). A correlação da expressão gênica de Phospholipase $C$ zeta $(P L C \zeta)$ e $W W$ domain binding protein $2 N-$ Terminal Like (WBP2NL) no espermatozoide, com a qualidade seminal e fertilidade de 40 garanhões da raça Crioula foi avaliada, comprovando que a expressão do gene $P L C \zeta$ no espermatozoide equino pode desempenhar diversos papéis na fisiologia do sêmen, assim como pode tornar-se um biomarcador para a qualidade seminal e fertilidade do garanhão (Bueno et al., 2018).

Estudos moleculares com os genes Cysteine-Rich Secretory Protein 3 (CRISP3) e Spermatogenesis Associated 1 (SPATA1) têm sido realizados, demonstrando a sua associação com problemas de fertilidade em garanhões (Giesecke et al., 2010). O gene SPATA1 foi associado a taxa de prenhez em garanhões, ou seja, garanhões heterezigotos apresentaram uma taxa melhor de prenhez em relação aos homozigotos para este Polimorfismos de Nucleotideo Único (Giesecke, et al., 2009). Os genes que codificam proteínas secretoras ricas em cisteína equina (CRISPS) são promissores genes candidatos, pois estudos mostraram que as CRISPs desempenham papel na capacidade de fecundação. Uma relação positiva entre a proteína CRISP3 no plasma seminal de sete garanhões com a taxa de concepção no primeiro ciclo foi descrita (Novak et al., 2010). Este achado dá suporte ao estudo de Hamann et al. (2007), no qual foi demonstrado um incremento de 7\% nas taxas de fertilidade de garanhões que eram homozigotos para CRISP3.

Segundo Bueno et al. (2019) a expressão de Sperm Autoantigenic Protein 17 (SPA17) no espermatozoide equino pode ser utilizada como um marcador para a qualidade seminal e fertilidade do garanhão, assim como a expressão de $T N F-\alpha$ no espermatozoide equino pode ser utilizada como um marcador para velocidade espermática após a criopreservação.

O Androgen receptors $(A R s)$ é um fator de transcrição dependente que pertence à família de receptores esteróides classe 1 (Callewaert et al., 2003). Nos garanhões o gene $A R s$ está localizado no epidídimo e células da próstata, que são diretamente reguladas por andrógenos. $\mathrm{O} A R s$ é necessário para o desenvolvimento epididimal no equino (Hejmej et al., 2006).

O gene Cation channels of sperm - (Catsper 1) codifica uma proteína de canal de cálcio que é exclusiva dos espermatozoides (Loux et al., 2013). O Catsper 1 regula um canal de cátion específico do espermatozoide que é essencial para a motilidade espermática hiperativada (Darszon et al., 2011). No espermatozoide do garanhão, o RNAm de Catsper 1 foi identificado e a proteína Catsper 1 foi localizada na peça principal da cauda do espermatozoide (Loux et al., 2013). Apesar da presença do canal no espermatozoide equino, a relação entre motilidade hiperativada e o influxo de cálcio é fraca (Leemans et al., 2019).

Um estudo investigou as diferenças na expressão gênica entre embriões resultantes da fecundação com sêmen fresco ou criopreservado. Os embriões foram obtidos aos 8, 10 ou 12 dias após a ovulação de éguas inseminadas pós-ovulação em sucessivos ciclos com sêmen fresco ou sêmen criopreservado. O perfil transcricional de embriões obtidos com espermatozoides criopreservados diferiram dos embriões derivados de espermatozoide fresco em todos os dias, mostrando regulação negativa de genes envolvidos em vias biológicas relacionadas à oxidação fosforilação, ligação de DNA, replicação de DNA e resposta imune (Ortiz-Rodriguez et al., 2019).

Os espermatozoides maduros têm pouco citoplasma e uma cromatina altamente condensada enriquecida em protaminas. A presença de ácido ribonucleico (RNA) no espermatozoide ejaculado maduro foi demonstrada, pois ocorrem tanto a transcrição quanto a tradução, não no citoplasma dos espermatozoides maduros, mas nas mitocôndrias (Bianchi et al., 2019). Os espermatozoides maduros contêm vários tipos de RNAs acumulados em seus núcleos mitocôndrias (Bianchi et al., 2019). Inclui RNA mensageiro (mRNA), microRNA (miRNA), RNA de interferência (iRNA) e RNA antisense (Hosken et al., 2014). Após a fecundação, o espermatozoide fornece um genoma completo, altamente estruturado e marcado epigeneticamente que, junto com RNAs e proteínas, desempenha um papel distinto no desenvolvimento embrionário inicial (Bianchi et al., 2019).

Apesar dos avanços obtidos na análise transcricional de espermatozoides em diversas espécies, os estudos genéticos de espermatozoides de garanhões ainda são limitados (Suliman et al., 2018). A análise do transcriptoma de espermatozoides de garanhões foi realizada por Suliman et al. (2018) e permitiu a comparação da abundância de genes entre garanhões férteis e subférteis. Em resumo, a 
previsão da fertilidade dos garanhões é um problema importante na criação de cavalos e a análise das características do sêmen tem capacidade limitada para prever a fertilidade. Além disso, ainda existem poucos estudos genéticos sobre a fertilidade dos garanhões, que poderiam fornecer possibilidades e novas ferramentas que ajudariam a prever a fertilidade dos reprodutores.

\section{Considerações Finais}

Vários estudos sugerem que a expressão gênica está associada à fertilidade (Giesecke et al., 2009; Ruijter-Villani et al., 2013; Bastos et al., 2014; Centeno et al., 2018; Sylvia et al., 2012; Bueno et al., 2018), além de permitir que pesquisadores desenvolvam testes específicos de diagnóstico e elaborem medidas preventivas de manejo e tratamento (Brosnahan et al., 2010). Diferente de outras espécies domésticas de interesse zootécnico, os equinos são valorizados como indivíduo, o que leva a menores índices reprodutivos. Há uma necessidade crescente de otimizar o tratamento diagnóstico e terapêutico da infertilidade. Desta forma a compreensão aprofundada dos componentes gênicos será importante para auxiliar a desvendar a fisiologia da reprodução equina, auxiliando na compreensão da infertilidade nesta espécie.

\section{Referências}

Al-Ramadan S, Johnson G, Jaeger L, Brinsko S, Burghardt R. Distribution of integrin subunits, muc1 , and osteopontin in equine uterine epithelium and conceptuses during early pregnancy. Baltimore, v.28. 31, p.555, 2002.

Bastos HBA, Kretzmann NA, Santos GO, Esmeraldino AT, Fiala Rechsteiner S, Mattos MC, Neves AP. Gene expression of matrix metalloproteinases and LH receptors in mare follicular development. Theriogenology, v.82, p.1131-1136, 2014.

Bianchi E, Boekelheide K, Sigman M, Braun JM, Eliot M, Hall SJ, et al. Spermatozoal large RNA content is associated with semen characteristics, sociodemographic and lifestyle factors. PLoS ONE, v. 14, p.1-13, 2019.

Brosnahan MM, Brooks SA, Antczak DF. Equine clinical genomics: A clinician's primer. Equine Vet. J, v.42, p.658-670, 2010.

Bueno VCL, Bastos HBA, Centeno LAM, Kretzmann NA, Bertolini MB, Mattos RC, Fiala Rechsteiner S. The Role of PLC $\zeta$ and WPB2NL Gene expression in semen quality and fertility of stallions. J Equine Vet Sci, v.66, p.33, 2018.

Bueno VLC, Bastos HB, Centeno LAM, Larentis GR, Kretzmann Filho NA, Mattos RC, Fiala SME. Expressão de marcadores de qualidade seminal e fertilidade em garanhões da raça Crioula. RCPA, v.17, p.277-278, 2019.

Canisso IF, Rodriguez JS, Sanz MG, Coutinho da Silva MA. A clinical approach to the diagnosis and treatment of retained fetal membranes with an emphasis placed on the critically ill mare. J Equine Vet Sci, v.33, p.570-579, 2013.

Campos-Chillon F, Farmerie TA, Bouma GJ, Clay CM, Carnevale EM. Effects of aging on gene expression and mitochondrial DNA in the equine oocyte and follicle cells. Reprod Fert Develop, v.27, p. 925-933, 2015.

Centeno LAM, Bastos HBA, Bueno VLC, Trentin JM, Fiorenza MF, Fiala-Rechsteiner S, Kretzmann NA, Mattos RC, Rubin MIB. gene expression of mmp-1, mmp-2 and thf-a in the endometrium of mares with different degrees of fibrosis. J Equine Vet Sci, v.66, p.143, 2018.

Chowdhary BP, Paria N, Raudsepp T. Potential applications of equine genomics in dissecting diseases and fertility. Anim Reprod Sci, v.107, p.208-218, 2008.

Christoffersen M, Baagoe CD, Jacobsen S, Bojesen AM, Petersen MR, Lehn-Jensen H. Evaluation of the systemic acute phase response and endometrial gene expression of serum amyloid A and pro- and anti-inflammatory cytokines in mares with experimentally induced endometritis. Vet Immunol Immunopathol, v.138, p.95-105, 2010.

Christoffersen M, Woodward E, Bojesen AM, Jacobsen S, Petersen MR, Troedsson MH, LehnJensen H. Inflammatory responses to induced infectious endometritis in mares resistant or susceptible to persistent endometritis. BMC Vet Res, v.8, p.1-14, 2012.

Darszon, A, Nishigaki T, Beltran C, Claudia LT. Calcium channels in the development, maturation, and function of spermatozoa. Physiol Rev, v.91, p.1305-1355, 2011. 
Fumoso E, Aguilar J, Giguère S, David O, Wade J, Rogan D. Interleukin-8 (IL-8) and 10 (IL-10) mRNA transcriptions in the endometrium of normal mares and mares susceptible to persistent postbreeding endometritis. Anim Reprod Sci, v.94, p.282-285, 2006.

Fumoso E, Giguère S, Wade J, Rogan D, Videla-Dorna I, Bowden RA. Endometrial IL-1 $\beta$, IL-6 and TNF- $\alpha$, mRNA transcriptions in mares resistant or susceptible to persistent post-breeding endometritis. Effects of estrous cycle, artificial insemination and immunomodulation. Vet Immunol Immunopathol, v. 96, p.31-41, 2003.

Garban Z, Gabriela G, Ghibu GD. Biomarkers: Theoretical Aspects and Applicative Peculiarities. Note II. Nutritional Biomarkers. J. Agroaliment. Processes Technol, v.12, p.349-356, 2006.

Giesecke K, Hamann H, Stock KF, Woehlke A, Sieme H, Distl O. Evaluation of SPATA1-associated markers for stallion fertility. Anim Genet, v.40, p.359-365, 2009.

Giesecke K, Sieme H, Distl O. Infertility and candidate gene markers for fertility in stallions: A review. The Vet J, v.185, p.265-271, 2010.

Gillies LK, Waelchli RO, Ruddock WDJ, Betteridge KJ, Lamarre J. Patterns of MUC1 expression in the equine endometrium and trophoblast during early pregnancy. Theriogenology, v.51, p.225, 1999.

Gouveia JJS, Regitano LCA. Extração de DNA. In: Regitano LCA, Niciura SCM, Ibelli AMG, Gouveia JJS. Protocolos em biologia molecular aplicada à produção animal. São Carlos: Embrapa Pecuária Sudeste, v.1, p.3-8, 2007.

Gradil C, Yoon S, Brown J, He C, Visconti P, Fissore R. PLCל: A marker for stallion fertility? Anim Reprod Sci, v.94, p.23-25, 2006.

Hamann H, Jude R, Sieme H, Mertens U, Töpfer-Petersen E, Distl O, Leeb T. A polymorphism within the equine CRISP3 gene is associated with stallion fertility in Hanoverian warmblood horses. Anim Genet, v.38, p.259-264, 2007.

Hejmej A, Wiszniewska B, Kosiniak-Kamysz K, Sadowska J, Bilin' ska B. The presence of androgen receptors in the epididymis and prostate of the stallion and cryptorchid horse - A preliminary study. Vet J, v.171, p.373-379, 2006.

Hinrichs K. Assisted reproduction techniques in the horse. Reprod Fert Develop, v. 25, p.80-93, 2013.

Hosken DJ, Hodgson DJ. Why do sperm carry RNA? Relatedness, conflict, and control. Trends Ecol Evol, v.29, p.451-5, 2014.

Ing NH, Forrest DW, Love CC, Varner DD. Dense spermatozoa in stallion ejaculates contain lower concentrations of mRNAs encoding the sperm specific calcium channel 1, ornithine decarboxylase antizyme 3, aromatase, and estrogen receptor alpha than less dense spermatozoa. Theriogenology, v.82, p. 347-353, 2014.

Jaworska J, Janowski T. Expression of proinflammatory cytokines IL-1 $\beta$, IL-6 and TNF $\alpha$ in the retained placenta of mares. Theriogenology, v.126, p.1-7, 2019.

Johnson GP, Lloyd AT, O'Farrelly C, Meade KG, Fair S. Comparative genomic identification and expression profiling of a novel $\beta$-defensin gene cluster in the equine reproductive tract. Reprod Fert Develop, v.28, p.1499-1508, 2016.

Kalpokas I, Mattos R, C, Cavestany D, Martínez MN, Perdigón F, Meikle A. Effect of side of the corpus luteum and pregnancy on estrogen and progesterone receptor expression and localization in the endometrium of mares. Theriogenology, v.114, p.221-228, 2018.

Klein C, Troedsson MH. Transcriptional profiling of equine conceptus reveals new aspects of embryomaternal communication in the horse. Biol Reprod, v.84, p.872-885, 2011.

Klohonatz KM, Hess AM, Hansen TR, Squires EL, Bouma GJ, Bruemmer JE. Equine endometrial gene expression changes during and after maternal recognition of pregnancy1. Anim Sci J, v.93, p.3364337, 2015.

Klonisch T, Steger K Kehlen, A Allen WR, Froehlich C, Kauffold J, Bergmann M, HombachKlonisch S. INSL3 ligand-receptor system in the equine testis. Biol Reprod, v.68, p.1975-1981, 2003.

Leemans B, Stout TAE, De Schauwer C, Heras S, Nelis H, Hoogewijs M, Van Soom A, Gadella BM. Update on mammalian sperm capacitation: how much does the horse differ from other species? Reproduction, v.157, p.181-197, 2019.

Leisinger CA, Klein C, Markle ML, Premanandan C, Sones JL, Pinto CRF, Paccamonti DL. Altered gene expression in embryos and endometrium collected onday 8 of induced aluteal cycles in mares. Theriogenology, v.128, p.81-90, 2019.

Leon PMM, Campos VP, Kaefer C, Begnin KR, Mcbride JA, Dellagostin AO, Seixas K, Deschamps JC, Collares T. Expression of apoptotic genes in immature and in vitro matured equine oocytes and cumulus cells. Zygote, v.21, p.279-285, 2011. 
Loux S. Hyperactivated motility of stallion spermatozoa. Dissertation (Doctor of Philosophy) - Texas A\&M University, Texas, 2013.

Lüttgenau J, Imboden I, Wellnitz O, Romer R, Scaravaggi I, Neves AP, Borel N, Bruckmaier RM, Janett F, Bollwein H. Intrauterine infusion of killed semen adversely affects uterine blood flow and endometrial gene expression of inflammatory cytokines in mares susceptible to persistent breedinginduced endometritis. Theriogenology, v.15, p.18-30, 2021.

Mortensen CJ, Choi YH, Ing NH, Kraemer DC, Vogelsang MM, Hinrichs K. Heat shock protein 70 gene expression in equine blastocysts after exposure of oocytes to high temperatures in vitro or in vivo after exercise of donor mares. Theriogenology, v.74, p.374-83, 2010.

Novak S, Smith TA, Paradis F, Burwash L, Dyck MK, Foxcroft GR, Dixon WT. Biomarkers of in vivo fertility in sperm and seminal plasma of fertile stallions. Theriogenology, v.74, p.956-67, 2010.

Ortiz-Rodriguez JM, Ortega-Ferrusola C, Gil MC, Martín-Cano FE, Gaitskell-Phillips G, Rodríguez-Martínez H, et al. Transcriptome analysis reveals that fertilization with cryopreserved sperm downregulates genes relevant for early embryo development in the horse. PLOS ONE, v.14, p.1-24, 2019. Polenz MF, Pereira GR, Augusto CG, Fiala SR. Gene expression before and after vitrification of equine CCO's. J Equine Vet Sci, v.41, p.76-77, 2016.

Ruijter-Villani M, van Boxtel PRM, Stout TAM. Fibroblast growth factor-2 expression in the preimplantation equine conceptus and endometrium of pregnant and cyclic mares. Theriogenology, v.80, p.979-989, 2013.

Schrimpf R, Dierks C, Martinsson G, Sieme H, Distl O. Genome-Wide Association Study Identifies Phospholipase C zeta 1 (PLCz1) as a Stallion Fertility Locus in Hanoverian Warmblood Horses. Plos One, v.29, p.10, 2014.

Sessions DR, Vick MM, Fitzgerald BP. Characterization of matrix metalloproteinase-2 and matrix metalloproteinase-9 and their inhibitors in equine granulosa cells in vivo and in vitro. Anim Sci J, v.87, p. 3955-66, 2009.

Sieme H, Distl O. Genomics and fertility in stallions. J Equine Vet Sci, v.32, p.467-470, 2012.

Silva LA, Klein C, Ealy AD, Sharp DC. Conceptus-mediated endometrial vascular changes during early pregnancy in mares: an anatomic, histomorphometric, and vascular endothelial growth factor receptor system immunolocalization and gene expression study. Reproduction, v.4, p.593-603, 2011.

Smits K, De Coninck DIM, Van Nieuwerburgh F, Govaere J, Van Poucke M, Peelman L, et al. The Equine Embryo Influences Immune-Related Gene Expression in the Oviduct1. Biol Reprod, v.94, p.1-8, 2016.

Sylvia J, Bedford G, Lori A, Mc P, Dickson D, Varner MS. Characterization of Equine Phospholipase C Zeta: A Review and Preliminary Results on Expression Defects in Subfertile Stallions. J Equine Vet. Sci, v.32, p.445-450, 2012.

Varner DD, Love CC, Brinsko SP, Blanchard TL, Hartman DL, Bliss SB, Carroll BS, Eslick MC. Semen Processing for the Subfertile Stallion. J Equine Vet Sci, v.28, p.677-685, 2008.

Zambrano F, Aguila L, Arias ME, Sánchez R, Felmer R. Improved preimplantation development of bovine ICSI embryos generated with spermatozoa pretreated with membrane-destabilizing agents lysolecithin and Triton X-100. Theriogenology, v.86, p.1-9, 2016. 